\title{
Ear asymmetry in reaction time to musical sounds
}

\author{
HOWARD J. KALLMAN and MICHAEL C. CORBALLIS \\ McGill University, Montreal, Quebec, Canada H3C $3 G 1$
}

\begin{abstract}
Dichotic pairs of musical sounds were presented to 16 right-handed subjects, who were instructed to depress a reaction-time (RT) button when a target sound occurred in either ear. Four blocks of 36 trials were presented. During the first block, RTs to left-ear targets were significantly faster than those to right-ear targets. There were no significant ear differences during the second, third, or fourth blocks. Possible explanations for the limited duration of the left-ear advantage, and its implications for models proposed to explain the basis of RT asymmetries, are discussed.
\end{abstract}

Dichotic listening experiments have demonstrated that when two different messages are presented simultaneously to different ears, that arriving at one of the ears may be more efficiently processed than that arriving at the other ear. For example, verbal messages presented to the right ear are more accurately recalled (Kimura. 1961. 1967) or later recognized (Broadbent \& Gregory, 1964) than are verbal messages presented simultaneously to the left ear. Certain nonverbal messages such as musical patterns (Dee, 1971; Kimura, 1964), sonar sounds (Chaney \& Webster, 1966). environmental sounds (Curry, 1967), and musical chords (Gordon, 1970) are more efficiently processed when presented to the left ear.

In order to explain these right- and left-ear advantages (REAs and LEAs, respectively), two assumptions are typically invoked. The first is that the contralateral pathways from ear to cortex are more efficient than the ipsilateral ones, especially with dichotic presentation (Kimura, 1967); indeed, there is some evidence that contralateral input may actually occlude ipsilateral input (Milner, Taylor, \& Sperry, 1968). Secondly, it is assumed that the human brain is functionally asymmetrical, with the left hemisphere typically speciatized for verbal processing and the right hemisphere for certain kinds of nonverbal processing. Theories differ with respect to the level of processing at which the asymmetries are thought to occur. Some have suggested that the asymmetries are primarily perceptual (e.g., Bryden, 1967; Kimura, 1967), others have emphasized asymmetries at the level of memory (e.g.. Satz, Achenbach, Pattishall, \& Fennell, 1965).

This research was supported by a grant from the National Research Council of Canada to Michael C. Corballis. Thanks are duc to Dr. Chet Olson for his helpful suggestions and to Gary Bernstein for writing the computer programs. The authors acknowledge the use of the computer-based laboratory of the McGill University Department of Psychology, supported by the National Research Council of Canada, the F.C.A.C. program of the Quebec Ministry of Education, and the McGill University Graduate Facults. M. C. Corballis' complete address: Department of Puchologs. McGill University, P.O. Box 6070, Station 'A, Montreal. Quehec. Canada H3C 3G1. while still others have argued for attentional asymmetries (e.g., Kinsbourne, 1970, 1973; Oxbury, Oxbury, \& Gardiner, 1967; Treisman \& Geffen, 1968).

Recently, it has been shown that the REA for verbal stimuli applies not only to the accuracy of performance, but also to speed. Springer (1971) presented dichotic pairs of consonant-vowel syllables and had her subjects press a button whenever they heard a particular target syllable in either ear. Reaction time (RTs) were faster and errors were fewer when the target occurred in the right ear than when it occurred in the left ear. The investigation of $\mathrm{RT}$ as well as accuracy differences potentially offers a more penetrating analysis of the mechanisms underlying lateral asymmetries than does the study of accuracy differences alone. It therefore seemed of interest to establish whether one could demonstrate a left-ear superiority in an RT paradigm, using nonverbal stimuli. In the present study, subjects listened for a target among dichotically presented musical sounds. The sounds were all of the same pitch, but were played on different instruments.

\section{METHOD}

\section{Subjects}

Sixteen right-handed McGill University students with no known history of hearing disorder volunteered to serve as subjects. Eight were male and eight female, with ages ranging from 17 to 23 years.

\section{Apparatus and Procedure}

The dichotic tape eniployed in this study was patterned after that used by Springer (1971). Tape recordings of the note $A(440 \mathrm{~Hz})$ played on four different instruments--bassoon, viola, piano, and cello-were produced. The note produced on the cello was plucked at the harmonic. The taped samples of each instrument were read in to a PDP-11 computer equipped with a program designed to store prespecified $500-\mathrm{msec}$ samples of each instrument on Dectape (the initial $500 \cdot \mathrm{msec}$ segment of each musical note was used so as to preserve the attack transients of each instrument). A pulse generated by the computer and occurring every $6.5 \mathrm{sec}$ was recorded onto the third channel of a Sony TC-366-4 four-channel tape deck, and the previously stored samples of musical notes were entered into memory along with instructions specifying the output sequence of dichotic pairs. The pulse recorded onto the third channel of the tape deck was used to retrieve each dichotic stimulus 
pair, which was then recorded onto the first and second channels of the tape deck. Since pulses occurred every $6.5 \mathrm{sec}$ and stimulus pairs lasted $0.5 \mathrm{sec}$, there was an interstimulus interval of $6 \mathrm{sec}$.

One block of 24 dichotic stimulus pairs and four blocks of 36 dichotic stimulus pairs were recorded. There were 12 possible pairwise permutations of the four musical sounds and each of these occurred in random order an equal number of times within each block. No stimulus was paired with itself. The probability of a given stimulus appearing on a given channel on a particular trial was .25 ; thus the probability of a given stimulus appearing in either ear on a particular trial was .50 .

Pilot work indicated that while subjects generally recognized the sounds as notes produced by musical instruments, one sound was sometintes confused for another. Since the note produced on the cello was the most easily recognized sound of the four, the cello was chosen to serve as target.

At the beginning of the experimental session, each subject was familiarized with the musical sounds employed in the experiment. The experimental task was then explained. The subject was told to depress a response button whenever he heard the target sound. Speed and reasonable accuracy were emphasized. Each subject was then given a practice block consisting of 24 dichotic pairs. During the practice block, each subject was instructed to use the index finger on one hand to respond during half of the trials and the index finger on the other hand to respond during the other half. Subjects who showed noticeable difficulty during the practice block were reintroduced to the stimuli and allowed to repeat the practice block. The few subjects who did repeat the practice block had no trouble during the second practice block.

Following practice, four experimental blocks, each consisting of 36 trials, were administered. The four experimental blocks were counterbalanced for hand used to respond and headphone orientation. The experimental conditions for half the subjects were counterbalanced in an ABBA order for headphones and ABAB order for response hand; the other half were counterbalanced in an $A B A B$ order for headphone orientation and ABBA order for response hand.

$\mathrm{RTs}$ were recorded in a room adjacent to the testing room by a Hewlett-Packard electronic printout timer. The pulse previously recorded on the tape deck was amplified and transmitted to a voice key which triggered the timer. The pulse occurred at a constant interval of approximately $315 \mathrm{msec}$ prior to the onset of each stimulus pair. When amplified, the pulse caused the voice key to produce an audible click, which, although not transmitted over the headphones, was loud enough to act as a warning signal indicating to subjects the beginning of a trial.

Table 1

Reaction Time Scores as a Function of Experimental Block and Ear of Target (Median Reaction Time in Milliseconds)

\begin{tabular}{|c|c|c|c|c|c|c|c|c|}
\hline \multirow[b]{2}{*}{ Subject } & \multicolumn{2}{|c|}{ Block 1} & \multicolumn{2}{|c|}{ Block 2} & \multicolumn{2}{|c|}{ Block 3} & \multicolumn{2}{|c|}{ Block 4} \\
\hline & $\begin{array}{c}\text { Left } \\
\text { Ear }\end{array}$ & $\begin{array}{l}\text { Right } \\
\text { Ear }\end{array}$ & $\begin{array}{l}\text { Left } \\
\text { Ear }\end{array}$ & $\begin{array}{c}\text { Right } \\
\text { Ear }\end{array}$ & $\begin{array}{l}\text { Left } \\
\text { Ear }\end{array}$ & $\begin{array}{c}\text { Right } \\
\text { Ear }\end{array}$ & $\begin{array}{l}\text { Left } \\
\text { Ear }\end{array}$ & $\begin{array}{c}\text { Right } \\
\text { Ear }\end{array}$ \\
\hline 1 & 399 & 553 & 520 & 447 & 456 & 423 & 422 & 418 \\
\hline 2 & 629 & 662 & 435 & 445 & 348 & 410 & 412 & 423 \\
\hline 3 & 1017 & 1253 & 982 & 922 & 838 & 803 & 703 & 667 \\
\hline 4 & 688 & 649 & 630 & 623 & 1137 & 979 & 855 & 903 \\
\hline 5 & 593 & 612 & 494 & 558 & 546 & 502 & 469 & 439 \\
\hline 6 & 595 & 762 & 623 & 746 & 572 & 775 & 749 & 754 \\
\hline 7 & 786 & 779 & 777 & 790 & 904 & 914 & 875 & 790 \\
\hline 8 & 651 & 599 & 686 & 672 & 616 & 668 & 656 & 683 \\
\hline 9 & 817 & 979 & 809 & 925 & 485 & 581 & 556 & 741 \\
\hline 10 & 471 & 486 & 422 & 479 & 372 & 395 & 371 & 342 \\
\hline 11 & 618 & 678 & 606 & 544 & 622 & 537 & 608 & 553 \\
\hline 12 & 692 & 775 & 447 & 430 & 498 & 483 & 483 & 467 \\
\hline 13 & 726 & 808 & 762 & 744 & 750 & 808 & 635 & 680 \\
\hline 14 & 450 & 640 & 507 & 467 & 551 & 572 & 426 & 448 \\
\hline 15 & 653 & 724 & 609 & 588 & 489 & 511 & 554 & 497 \\
\hline 16 & 476 & 502 & 451 & 450 & 476 & 473 & 435 & 387 \\
\hline Mean & 641 & 716 & 610 & 614 & 604 & 615 & 576 & 575 \\
\hline
\end{tabular}

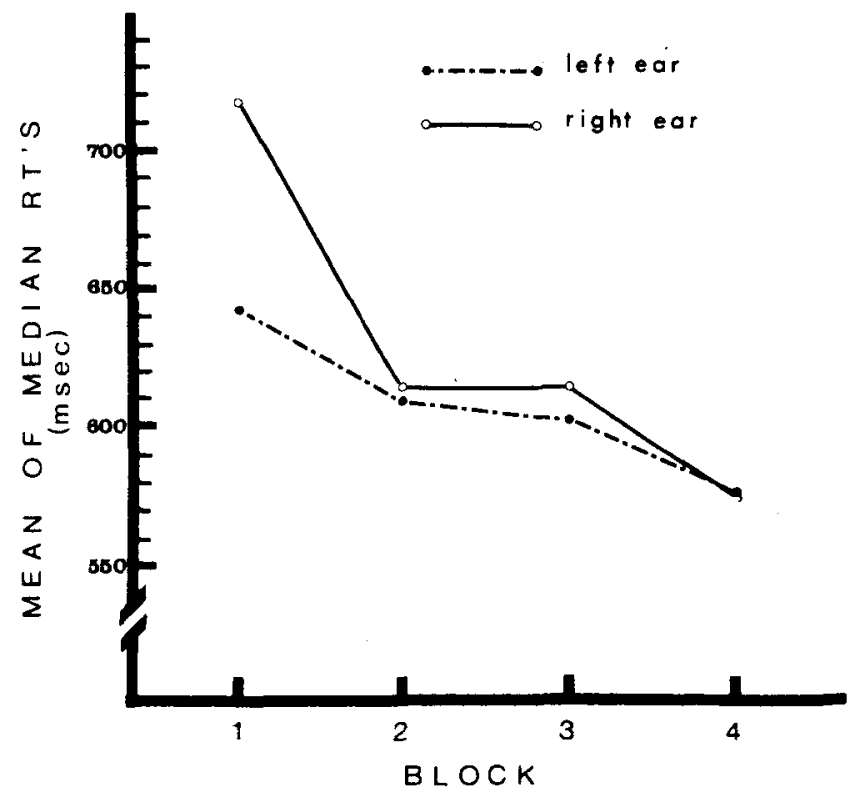

Figure 1. Interaction between experimental blocks and ears.

Koss Pro-4 headphones were used to deliver the dichotic stimulus pairs. which were amplitied using a Shure Solophone headphone booster.

\section{RESULTS}

Median RTs for each ear within each block of trials were computed for each subject, and are presented in Table 1. These RT scores were subjected to analysis of variance. A one-tailed test of the hypothesis that targets presented to the left ear would yield shorter RTs fell short of significance, $F(1,8)=2.85$, $.05<p<.10$. However, there was a significant interaction between ears and blocks. $F(3,24)=4.87$. $p<.01$. Tests of simple effects (Winer, 1971) indicated a significant LEA during the first block of trials, $F(1,25)=15.29, p<.001$, but no significant ear differences in the second, third, or fourth blocks, $\mathrm{F}<1$ in each case. These effects are shown in Figure 1 .

There was no signiticant difference between hands. $\mathrm{F}<1$, or any significant interaction between hands and ears, $F(1,14)=1.46$.

On average, $96 \%$ of the targets were detected. The Wilcoxon matched pairs signed ranks test failed to reveal significant differences in accuracy between the ears, either overall or within blocks. False alarms occurred on less than $5 \%$ of the trials.

\section{DISCUSSION}

Using $R T$ as the dependent measure, the present experiment has demonstrated an LEA, but of limited duration, for the recognition of dichotically presented musical notes. The finding of an LEA parallels previous demonstrations of an LEA in error rate to 
musical and other nonverbal sounds. The failure in the present experiment to find any differences in error rate between ealrs may have been due to the low number of errors. This suggests that RT may be a more sensitive measure of asymmetry than error rate. as Springer (1973) has claimed.

That the LEA in the present experiment disappeared after the first block of trials is not inconsistent with previous evidence. Using musical patterns as stimuli and error rate as the dependent measure. Spellacy (1970) found that an LEA evident during the tirst half of an experiment disappeared during the second half. In order to explain the short duration of the LEA in his study, Spellacy suggested that attention may play a role in maintaining asymmetries. This idea has received support from Kinsbourne $(1970,1973)$, who suggested that activation of one or the other cerebral hemisphere might direct attention to the opposite side of the body. If presentation of musical sounds induces a musical "set," and so activates the right hemisphere, one would therefore expect attention to be directed primarily to the left ear. With time, however, one might expect the musical set to decline. Consequently, the differential activation between hemispheres might be expected to disappear, and with it the advantage of the left ear over the right.

An alternative explanation for the disappearance of the LEA is that the processing capacity of the right hemisphere declines with repeated stimulation, perhaps simply as a consequence of fatigue. Dimond and Beaumont (1972) have found evidence from performance on a visual task that one hemisphere may become fatigued independently of the other, particularly when the processing demands on the two hemispheres are unequal. The left hemisphere might perhaps compensate for right-hemisphere fatigue by increasing its share of processing. It may also be that the left hemisphere is able to process musical sounds as efficiently as the right hemisphere once a strategy or set to do so is developed. Thus, even in the absence of right-hemisphere fatigue, the left hemisphere may increase its processing share.

Bever and Chiarello (1974) have recently demonstrated an REA for the processing of musical sequences among musically sophisticated listeners, although naive listeners showed the usual LEA. Their interpretation is that the musically sophisticated processed the sounds analytically, which is a left-hemisphere mode, while the naive processed them holistically, a right-hemisphere mode. This interpretation emphasizes the sequential aspect of musical perception. and thus does not directly apply to the perception of the single-note stimuli we used in our study. However, it does illustrate the point that there may be left-hemisphere modes for the processing of stimuli that are normally considered to be processed by the right hemisphere. Their finding is also further evidence of the lability of the LEA for musical sounds.

It seems likely, therefore, that lateral asymmetries. at least in the processing of simple nonverbal stimuli, are not rigidly specified; rather, they may fluctuate in degree and perhaps even in direction. Whether these fluctuations are due primarily to variations in attention or set, or whether they depend more directly on fatigue or habituation, is a matter which requires further claritication.

\section{REFERENCES}

Bever, T. G.. \& Chiarello, R. J. Cerebral dominance in musicians and nonmusicians. Science, 1974, 185, 537-539.

Broadbent, D. E., \& Gregory, M. Accuracy of recognition for speech presented to the right and left ears. Quarterly Journal of Experimental Psychology, 1964, 16. 359-360.

BRYDEN, M. P. An evaluation on some models of laterality effects in dichotic listening. Oto-Laryngologia, 1967, 63, 595-604.

Chaney, R. B., \& Webster, J. C. Information in certain nultidimensional sounds. Joumal of the Acoustical Society of America, 1966, 40, 449-455.

Curry, F. A comparison of left-handed and right-handed subjects on verbal and non-verbal dichotic listening tasks. Cortex, $1967,3,343-352$.

DEE, H. L. Auditory asymmetry and strength of manual preterence. Cortex, 1971, 7, 236-245.

Dimond, S. J., \& Beaumont, J. G. On the nature of the interhemispheric effects of fatigue. Acta Psychologica, 1972, 36. 443-449.

Gordon, H. W. Hemispheric asymmetries in the perception of musical chords, Cortex, 1970, 6, 387-398.

Kimura, D. Cerebral dominance and the perception of verbal stimuli. Canadian Joumal of Psychology, 1961, 15, 166-171.

Kimura, D. Lett-right differences in the perception of melodies. Quanirly Joumal of Experimental Psychology. 1964, 16. 35.5-358.

Kimura, D. Functional asymmetry of the brain in dichotic listening. Cortex, 1967, 3. 163-178.

KinsBourne, M. The cerebral basis of lateral asymmetries in attention. Acta Psichologica, 1970. 33. 193-201.

KinsBourne, M. The control of attention by interaction between the cerebral hemispheres. In S. Kornblum (Ed.), Attention and performance. IV. New York: Academic Press, 1973.

Milner, B., Taylor, L., \& Sperry, R. W. Lateralized suppression of dichotically presented digits after commissural section in man. Science, 1968, 161. 184-186.

Oxbury, S., Oxbury, J., \& Gardiner, J. Laterality effects in dichotic listening. Nature, 1967, 214, 742-743.

Satz, P., Achenbach, K., Pattishall, E., \& Fennell, E. Order of report. ear asymmetry and handedness in dichotic listening. Cortex, 1965, 1, 377-396.

SPELlaCy. F. Lateral preterences in the identitication of patterned stimuli. Joumal of the Acoustical Society of America, 1970. 47. 574-578.

Springer, S. P. Ear asymnetry in a dichotic detection task. Perception \& Psychophysics, 1971, 10, 239-241.

SPRINGER, S. P. Hemispheric specialization for speech opposed by contralateral noise. Perception \& Psychophysics. $1973,13,391-393$.

Treisman, A., \& Geffen, G. Selective attention and cerebral dominance in perceiving and responding to speech messages. Quarterly Journal of Experimental Psychology, 1968, 20. 139. 150 .

WINER, B. J. Statistical principles in experimental design (2nd ed.). New York: McGraw-Hill, 1971.

(Received for publication August 26, 1974; revision received December $10,1974$. 